\title{
ASSISTÊNCIA DE ENFERMAGEM AOS IDOSOS RESIDENTES EM INSTITUIÇÕES DE LONGA PERMANÊNCIA: UMA REVISÃO INTEGRATIVA
}

Yasmin de Fatima Aragão Mano; Universidade Federal de Roraima - UFRR; yasminmano@outlook.com Ana Luíza Amorim de Lima; Universidade Federal de Roraima - UFRR; analuizaamorimlima9@gmail.com Myllena Alencar da Silva; Universidade Federal de Roraima - UFRR; myllena25a@gmail.com Letícia Pacheco Silva; Universidade Federal de Roraima - UFRR; leti.psrr@gmail.com Raquel Voges Caldart; Universidade Federal de Roraima - UFRR; raquel.voges@ufrr.br

\section{RESUMO}

Introdução: $\mathrm{O}$ envelhecimento populacional é uma realidade no Brasil, neste contexto as instituições de longa permanência para idosos surgem como uma alternativa na oferta de cuidados contínuos para este público. Objetivo: Identificar o cuidado de enfermagem prestado aos idosos residentes nestas instituições. Metodologia: Trata-se de uma revisão integrativa realizada na base de dados Scientific Electronic Library Online, Literatura Latino-americana e do Caribe em Ciências da Saúde, Medical Literature Analysis and Retrieval System Online e U.S. National Library of Medicine, entre os anos 2015 a 2020. A busca dos artigos foi realizada em agosto de 2020, utilizando os descritores "instituição de longa permanência para idosos" e "cuidados de enfermagem". Resultados: Dentre os cuidados de enfermagem prestados aos idosos institucionalizados identificados nos 18 artigos selecionados para este estudo destacam-se, a estimulação cognitiva com a finalidade de promover o bem-estar e a saúde mental; realização de atividades em grupo para favorecer a socialização e proporcionar acolhimento e sensação de pertencimento; práticas de atividades físicas que contribuem para marcha e reduzem o risco de quedas; cuidados com a pele diminuindo o risco de ressecamento e lesões e; estimulação da ingesta hídrica para manutenção da saúde. Conclusão: Considerando o elevado percentual de idosos dependentes para atividades básicas de vida diária nas instituições de longa permanência, a equipe de enfermagem tem papel fundamental quando proporciona uma assistência integral e individualizada com vistas a melhorar a capacidade funcional, promover autonomia e independência e, consequentemente melhorar a qualidade de vida do idoso sob seus cuidados.

Palavras-chave: Instituições de longa permanência; Cuidados de enfermagem; Saúde do idoso. 